\title{
CONSIDERAÇÕES INICIAIS SOBRE LÓGICA E TEORIA LACANIANA
}

\author{
Marcelo Amorim Checchia ${ }^{1}$ \\ Instituto de Psicologia - USP
}

\begin{abstract}
No decorrer de seu ensino, Lacan não só fez referências a lógicos como Frege e Russell como extraiu da própria lógica um fundamento para a formalização da psicanálise. Mas por que Lacan recorre justamente à lógica para transmitir a psicanálise? Quais são as relações entre a lógica moderna e a experiência psicanalítica? Neste artigo, estaremos realizando uma primeira abordagem sobre essas questões.
\end{abstract}

Descritores: Psicanálise. Lógica (Filosofia). Lacan, Jacques, 1901-1981. Frege, Gottlob, 1848-1925.

$\mathrm{E}^{\mathrm{x}}$ xistem diversas maneiras de se abordar a especificidade do campo lacaniano. Isto não significa, contudo, que qualquer entrada nesse campo se realize facilmente. Não podemos, por exemplo, tratar do desejo na teoria lacaniana sem nos remetermos ao gozo, bem como estudar o sujeito sem nos referirmos ao Outro e ao Nome-do-pai, tal o entrelaçamento lógico dos termos criados e elaborados por Lacan. Há toda uma lógica que embasa o campo lacaniano. Sabe-se, inclusive, que Lacan fez algumas referências a lógicos como Frege e Russell, lógicos comprometidos com o desenvolvimento da lógica. Mas, tomando de empréstimo questões já formuladas por outros autores, "o que tinha a interpretação analítica a ganhar com uma lógica em que o enunciado proposicional é referido precisamente ao seu valor de verdade: o verdadeiro ou o falso? De que maneira, a partir disso, referir a ela

1 Psicanalista, mestrando no Departamento de Psicologia Clínica do Instituto de Psicologia - USP. Endereço eletrônico: marcelo_checchia@ hotmail.com 


\section{Marcelo Amorim Checchia}

as formações do inconscie nte?" (Doumit, 1996, p. 299). Ou ainda, "se as leis do inconsciente são tais como as descreve na Freud Traumdeutung, de que vale a lógica clássica? (...) $\mathrm{O}$ inconsciente não seria porventura o próprio ilógico?" (Darmon, 1994, pp. 169, 178). Como, portanto, a lógica pode promover algum enriquecimento para a psicanálise? Por que Lacan recorre à lógica para transmitir a psicanálise?

De início, pode-se dizer que Lacan se preocupou em fundamentar a psicanálise a partir da ciência e de sua própria experiência Assim disse ele em "Função e Campo da Fala e da Linguagem em Psicanálise" (1953/1998, p. 268): "se a psicanálise pode tornar-se uma ciência, (...), devemos resgatar o sentido de sua experiência". E em que consiste tal experiência? Consiste essencialmente em uma relação de linguagem, mas não uma relação natural, dual e sim uma relação artificial em que há um dispositivo. A relação analítica é uma relação artificial e não é possível pensar no "inconsciente como um objeto anterior a essa relação" (Nogueira, 1997a, p. 17). Esta é, segundo Nogueira, uma primeira posição marcada por Lacan, que traz como conseqüência a impossibilidade de se fazer um estudo ontológico do inconsciente. Se não era possível um estudo ontológico, era preciso encontrar condições para pensar a prática analítica. Lacan encontrou tais condições dentro da concepção científica moderna. ${ }^{2}$ É por isso que, como diz Nogueira (1997a, p. 17), há no texto de Lacan "uma grande dificuldade de comunicação, porque cada vez mais ele vai tentando formalizar a prática analítica numa linguagem artificial, que exige, portanto, um conhecimento daquilo que nós entendemos como linguagem artificial na modernidade". Mas como se deu, então, a construção dessa linguagem artificial na ciência moderna?

2 Em contraposição ao modelo experimentalista do qual Freud se serviu Nogueira (1997a, p. 16) chegou à conclusão de que "Lacan nos diz que a psicanálise se apresenta como outro tipo de saber, uma outra metodologia para pensar o que é exatamente o dispositivo que Freud inventou e que nos possibilita (...) investigar aquilo que Freud chamou de inconsciente. (...) Lacan se interessou em conceitualizar isso, (...) justamente agora não mais querendo inserir a psicanálise no contexto experimentalista, mas propondo uma questão para a própria ciência experimentalista diante do inconsciente e diante da prática analítica”. 


\title{
Breve histórico da lógica
}

A lógica tem sua origem na Grécia Antiga. O termo lógica foi empregado pela primeira vez pelos estóicos e por Alexandre de Afrodisia, mas Aristóteles já tratava da lógica em seu Órganon - conjunto de escritos sobre lógica - sob o termo analíticos (analytikós). Aristóteles não classificava a lógica como uma ciência, pois ela não é um conhecimento teorético nem prático de nenhum objeto. Segundo Chauí, para Aristóteles

\begin{abstract}
a lógica não se refere a nenhum conteúdo, mas à forma ou às formas do pensamento ou às estruturas dos raciocínios em vista de uma prova ou de uma demonstração. (...) Os Analíticos [de Aristóteles] buscam os elementos que constituem a estrutura do pensamento e da linguagem, seus modos de operação e relacionamento. (...) A lógica é uma disciplina que fornece as leis ou regras ou normas ideais do pensamento e o modo de aplicá-las na pesquisa e na demonstração da verdade. Nessa medida, é uma disciplina normativa, pois dá as normas para bem conduzir o pensamento na busca da verdade. (Chauí, 2002, p. 357)
\end{abstract}

Vemos, portanto, que a lógica se caracteriza como um instrumento do pensamento para o conhecer. Trata-se de um instrumento para as ciências, "pois somente ela pode indicar qual é o tipo de proposição, de raciocínio, de demonstração, de prova e de definição que uma determinada ciência deve usar" (Chauí, 2002, p. 357) - inclusive, o termo Órganon significa instrumento.

Bem, como o que nos interessa é o desenvolvimento da lógica moderna e o uso que Lacan faz dela, não é possível aqui aprofundar o estudo aristotélico sobre a lógica, cabendo-nos apenas apontar suas características na origem de sua concepção. Retome-mo-la então a partir do século XVII: foi a partir deste período que a relação entre lógica e linguagem foi se tornando cada vez mais clara.

Leibniz foi um dos grandes representantes deste período; inspirado na álgebra, mostrou que não é possível separar a lógica de um uso ordenado e regulado da linguagem. Ele encontrou na álgebra a possibilidade de desenvolver essa linguagem perfeita, livre de ambigüidades da linguagem cotidiana - isto porque a álgebra possui símbolos próprios e universais, isto é, sím- 
bolos que são transmitidos e compreendidos independentemente da língua que se fala. Assim, como afirma Chauí (1997, p. 194), "Leibniz propôs uma linguagem simbólica artificial, isto é, construída especialmente para garantir ao pensamento plena clareza nas demonstrações e nas provas".

Outro filósofo do mesmo período que desenvolveu a relação entre lógica e matemática foi Hobbes. Ele parte da noção de linguagem como convenção social, com a qual é possível fazer corresponder determinados sons com o significado lingüístico e mental. A função da lógica consistiria então em organizar e sistematizar o uso dessas convenções, de maneira a evitar a ambigüidade de cada palavra ou proposição.

Entretanto, foi somente nos meados do século XIX que esse ideal de uma lógica simbólica inspirada na linguagem matemática veio a se concretizar, através de Boole e de Morgan e, posteriormente, de Frege, Russell e Whitehead. Tais autores transformaram a lógica, abandonando as teorias aristotélicas por uma nova concepção de proposição lógica.

\section{A lógica matemática}

A história da lógica, na verdade, se confunde com a história da matemática. Pode-se dizer que a matemática é ainda mais antiga, uma vez que ela nasce com os fenícios a partir da necessidade de contar coisas e medir terrenos. Porém, os primeiros que transformaram a arte de contar e de medir em ciências foram os gregos, criando a aritmética e a geometria com o uso de números, figuras, relações e proporções.

A noção de prova matemática é fundamental para entendermos sua articulação com a lógica. A prova matemática é absoluta e irrefutável. Uma demonstração matemática segue regras universais e necessárias, de maneira que a demonstração de um teorema possa ser feita em qualquer época e qualquer lugar. $\mathrm{O}$ teorema de Pitágoras é um exemplo do valor da prova matemática. Pitágoras demonstra que seu teorema é verdadeiro para cada triângulo retângulo do universo. Segundo Singh (2000, p. 45), tal descoberta foi um marco na história da matemática pois desenvolveu a idéia de prova: 
uma solução matemática é uma verdade absoluta pois é o resultado de uma lógica encadeada. Conforme o autor,

A idéia de demonstração matemática clássica começa com uma série de axiomas, declarações que julgamos serem verdadeiras ou que são verdades evidentes. Então, através da argumentação lógica, passo a passo, é possível chegar a uma conclusão. Se os axiomas estiverem corretos e a lógica for impecável, então a conclusão será inegável. Esta conclusão é o teorema. Os teoremas matemáticos dependem deste processo lógico, e uma vez demonstrados eles serão considerados verdade até o final dos tempos. (Singh, 2000, p. 41)

Observa-se, portanto, que o avanço da matemática dependeu do uso da lógica. Ao mesmo tempo, a geometria e a álgebra contribuíram para o desenvolvimento da lógica matemática: a primeira, fornecendo o campo para o estudo das noções de axiomática e a segunda, um modelo para elaboração de um cálculo lógico.

Segundo Kneale e Kneale (1968/1991, p. 409), Leibniz já tinha compreendido que há alguma semelhança entre a conjunção e disjunção de conceitos e a adição e multiplicação de números, mas não chegou a usar tal compreensão para base de um cálculo lógico. Quem primeiro utilizou as fórmulas algébricas para exprimir relações lógicas foi Boole, em Mathematical Analysis of Logic. Boole afirma que

a característica definitiva de um Cálculo verdadeiro consiste em o seu método se basear sobre o emprego de símbolos, cujas leis de combinação são conhecidas e gerais e cujos resultados admitem uma interpretação consistente. (...) É fundamentado neste princípio geral que eu me proponho estabelecer um Cálculo Lógico, e pretendo ao mesmo tempo que ele tenha um lugar entre as formas aceitas de Análise Matemática, sem considerar no entanto que pelos seus objetos e pelas suas técnicas tem que estar atualmente isolado.

(...) Estas investigações propõe uma doutrina acerca da linguagem que é muito interessante. A linguagem é descrita aqui não como uma simples coleção de sinais, mas como um sistema de expressões, cujos elementos estão sujeitos às leis do pensamento que elas representam. Que estas leis sejam rigorosamente matemáticas como as leis que governam os conceitos puramente quantitativos de espaço e de tempo, de número e de grandeza, é uma conclusão que eu não hesito em submeter ao mais exato dos escrutínios. (citado por Kneale \& Kneale, 1968/1991, p. 411) 
Neste trecho fica clara a inovação provocada por Boole no campo da lógica. Desta maneira, ele foi responsável por ter causado a renovação da lógica como uma ciência independente. Boole teve a intenção de demonstrar que a lógica era uma parte da matemática, ou melhor, ele pretendeu "apresentar a lógica como um cálculo semelhante em alguns aspectos à álgebra numérica" (Kneale \& Kneale, 1968/1991, p. 441). Neste sentido, ele pensava como Leibniz, que a característica da matemática era a construção de cálculos e que havia alguns cálculos que poderiam ser interpretados sem referências a números ou quantidades.

Quem provocou outra grande inovação frente à lógica foi Frege. Diferentemente de Boole, que considerava a lógica como parte da matemática, Frege dizia que a aritmética era idêntica à lógica. Até então, ninguém ainda havia demonstrado como a lógica poderia se desenvolver num sistema que se poderia chamar também aritmética. Frege construiu assim um manual de ideografia ou escritura conceitual, libertando a lógica das relações com a gramática da linguagem cotidiana. Desta maneira, a terminologia ambígua de "sujeito" e "predicado" deu lugar "a uma distinção mais satisfatória de formas proposicionais de acordo com a teoria das funções" (Kneale \& Kneale, 1968/1991, p. 442). Seu objetivo era, portanto,

a construção de uma linguagem formalizada do pensamento puro, quer dizer, um sistema de notação mais regular do que a linguagem de todos os dias e melhor adaptado para garantir a exatidão na dedução, uma vez que permite apenas o que é essencial, nomeadamente o conteúdo conceitual enquanto oposto à ênfase retórica. (p. 483)

Este objetivo, apesar de aparentemente simples, proporcionou uma virada fundamental no desenvolvimento da lógica. Segundo os autores, a obra Begriffsschrift contém tudo que é essencial em lógica moderna, sendo a obra mais importante sobre lógica. Sua maior contribuição consiste no uso de quantificadores para ligar variáveis 3 - principal característica do simbolismo

3 Encontra-se a demonstração desta contribuição de Frege na obra de Kneale e Kneale $(1968 / 1991)$. 
lógico moderno - ultrapassando o uso da linguagem vulgar como também o simbolismo do tipo algébrico usado por Boole.

Isto significa que a lógica moderna, em contraposição à lógica antiga que considerava o conteúdo das proposições -, preocupa-se menos com a realidade dos objetos referidos pela proposição para tornar-se plenamente formal, por meio do puro simbolismo do tipo matemático e do cálculo simbólico. Assim, da mesma maneira que o matemático ocupa-se com os objetos criados pelas operações matemáticas, o lógico moderno cria os símbolos e as operações que constituem a proposição. A construção deste simbolismo permite então à lógica descrever as formas, as propriedades e as relações das proposições. Deste modo, a lógica foi se tornando cada vez mais uma ciência formal da linguagem, mas de uma linguagem elaborada por ela mesma a partir da matemática - isto é, uma linguagem simbólica na qual cada símbolo é um algoritmo, apresentando um único sentido. Portanto, como afirma Chauí,

ao manter a proximidade e a relação com a matemática, a lógica passou a ser entendida como avaliadora da verdade ou falsidade do pensamento, concebido como uma construção intelectual. Ora, se o pensamento constrói seus próprios objetos, em vez de descobri-los ou contemplá-los, essa construção, segundo os próprios matemáticos, faz com que a matemática deva ser entendida como um discurso ou como uma linguagem que obedece a certos critérios e padrões de funcionamento. Assim sendo, a lógica adotou para si o modelo de um discurso ou de uma linguagem que lida com puras formas sem conteúdo e tais formas são símbolos do tipo matemático (algoritmos).

(...) a lógica passou a dedicar-se menos ao pensamento e muito mais à linguagem, seja como tradução, representação ou expressão do pensamento. Seu objeto passou a ser o estudo de um tipo determinado de discurso: a proposição e as relações entre proposições. (1997, p. 197)

\section{Frege e Lacan}

A relação entre lógica e psicanálise é, no mínimo, complexa e paradoxal. Se a lógica tornourse plenamente formal a partir do uso de símbolos 
matemáticos universais, como utilizá-la no campo da psicanálise, uma vez que, como afirma Nogueira (1997b, p. 14) a experiência analítica, a relação entre analista e analisante, é singular a cada encontro, não podendo ser objetivada, generalizada e universalizada? Se a experiência analítica é irreversível, irrepetível, como tal experiência pode se constituir numa ciência transmissível para muitas pessoas? Observa-se, assim, que a busca de compreensão desta articulação entre lógica e psicanálise traz consigo questões concernentes à prática analítica e à epistemologia.

É a partir da linguagem que Lacan vai estabelecer essa relação entre lógica e psicanálise. Ele situa o campo da psicanálise como o campo da relação de linguagem - já que se trata da relação entre falantes -, e ao especificar o campo da psicanálise, ao mesmo tempo Lacan a situa epistemologicame nte. Foi Freud quem criou a psicanálise, quem, conforme Nogueira (1997b, p. 17), "inaugurou um método novo para pensar (...) a realidade humana que estava ocorrendo entre ele e seus pacientes." Mas foi Lacan quem se esforçou para situá-la epistemologicamente, como em "Função e Campo da Fala e da Linguagem na Psicanálise", texto no qual ele aponta o símbolo e a linguagem como fundamento e limite da psicanálise. Assim, enquanto Freud inaugurou um método novo, Lacan pretendeu constituir a psicanálise como uma ciência nova, respeitando a originalidade de Freud.

Lacan destacou que a posição analítica é diferente do mito, da filosofia e da ciência experimental na medida que não constitui um conhecimento formado transmissível para os outros. Como afirma Nogueira (1997b, p. 23), "há uma noção a respeito da realidade que é transmitida universalmente, tanto pelo mito, quanto pela filosofia e pelo experimento, que a psicanálise não vai poder aproveitar", pois cada análise é uma experiência única. Não é possível dizer ao analisante que faça o que seu analista fez em sua própria análise porque a experiência psicanalítica não é uma experiência de conhe-

4 Como afirma o autor, "não adiantava tentar agir diretamente sobre o corpo, sobre o organismo daqueles pacientes [como faze m os médicos], mas era preciso estabelecer uma relação de linguagem". 
cimento. O inconsciente emerge na relação de fala: "a linguagem é a condição do inconsciente", é a tese de Lacan (1970, p. 39).

A partir daí é possível perceber a diferença entre a relação analítica e o que podemos dizer desta relação. $\mathrm{O}$ que dize mos depois da experiência não é a experiência mesma, por isso não basta que se transmita conhecimento dessa experiência para que uma pessoa realmente viva esta experiência. Se isso fosse possível, bastaria ler a "Interpretação dos Sonhos" para fazer uma auto-análise com o conhecimento adquirido dos processos oníricos. Nesse sentido, como afirma Nogueira (1997b, p. 81), "eu preciso do Outro para entrar em contato com minha divisão isoladamente". É isso que, segundo Nogueira (1997b), caracteriza propriamente a experiência analítica e o campo da psicanálise, inaugurando uma nova forma de saber sobre a realidade humana e uma nova metodologia desconhecida até Freud.

Nogueira (1997b, pp. 81-87) também descreve de maneira muito esclarecedora como foi se dando a construção teórica da psicanálise a partir da experiência analítica criada por Freud. Acompanhemo-lo, aproveitando e inserindo outros textos conforme a necessidade.

Percorrendo a produção freudiana encontramos vários relatos clínicos, isto é, descrições dos encontros entre Freud e os pacientes. Há nesses relatos a transmissão de experiências para que as pessoas da época acompanhassem a novidade de sua metodologia utilizada em suas investigações. Para tal transmissão Freud utilizava a linguagem natural, no caso a língua alemã. Entretanto, ao mesmo tempo Freud tentava encontrar palavras ou criar conceitos que pudessem simplificar a experiência clínica, como, por exemplo, o conceito de transferência. Desta maneira, ele pôde utilizar este termo para transmitir algo que ocorria em várias experiências, sem assim precisar descrever pormenorizadamente cada encontro com cada paciente. Trata-se, portanto, de um esforço de abstração, na qual conceitos passam a ser criados para simplificar múltiplas experiências. Isto se torna muito mais evidente em Lacan, uma vez que ele não se refere às descrições clínicas para pensar na clínica. Ele privilegia justamente um nível de transmissão que utiliza ao má- 


\section{Marcelo Amorim Checchia}

ximo o processo de abstração, o nível de transmissão matêmica, no qual símbolos matêmicos funcionam como simplificadores da prática analítica.

Vale observar que esta é uma preocupação presente em praticamente toda obra de Lacan, principalmente após o Congresso de Roma em 1953. Vejam que desde o Seminário 1 - Os Escritos Técnicos de Freud já encontramos articulações diretas com a matemática:

Ao longo das idades, através da história humana, assistimos a progressos a propósito dos quais nos enganaríamos ao acreditar que são progressos das circunvoluções. São os progressos da ordem simbólica. Sigam a história de uma ciência como a Matemática. (...) O progresso da matemática não é um progresso da potência do pensamento humano. É no dia em que um senhor pensa em inventar um signo como este, $\sqrt{ }$, ou como este, $\int$, que dá coisa boa. A Matemática é isso.

Estamos numa posição de natureza diferente, mais difícil. Porque lidamos com um símbolo extremamente polivalente. Mas é apenas na medida em que chegarmos a formular adequadamente os símbolos da nossa ação que daremos um passo adiante. (Lacan, 1954/1981, p. 313)

Nota-se, portanto, que Lacan procurou formalizar a psicanálise de maneira analógica à matemática moderna e o que Lacan aprecia em Frege é justamente a invenção da escrita ideográfica ${ }^{5}$ como uma tentativa de manter a exatidão na dedução. Assim, como diz Nogueira (2002):

o pensar matemático tenta substituir a falta a ser pelos seus símbolos: é a linguagem criativa, universal, da matemática para lidar com a falta. O que a matemática faz para lidar com a falta é o que fazemos para lidar com o desejo. O processo de causação é o processo de substituição da falta por um símbolo, o que é uma analogia do processo matemático.

Outro bom exemplo, destacado por Nogueira (1997b, p. 85), desse esforço de abstração de Lacan e que nos remete ao pensar matemático é a re-

5 Cujo mérito é o de "não se contentar em depreender as leis lógicas, 'os juízos do pensamento puro' que entram em jogo na dedução matemática: ela se empenha sobretudo em apresentá-los sob a forma de um sistema dedutivo, em que aparecem, de maneira explícita, as conexões mútuas entre essas leis, o que insere a lógica na via da axiomatização" (Doumit, 1996. p. 298). 
dução de todas as cadeias de associações livres dos analisantes ao símbolo $S_{2}$, enquanto $S_{1}$ simboliza a exterioridade do significante (o significante que intervém na bateria de significantes $\mathrm{S}_{2}$ ). Com isto simplifica-se todas as variações existentes nas associações de cadeia de significantes de cada analisante, possibilitando assim o diálogo entre os analistas sem a necessidade de relato de toda a história de um caso clínico para transmissão do que é próprio da experiência analítica.

Porém, é preciso deixar claro que essa construção da matemática é uma construção da consciência, diferente de uma construção inconsciente, como num ato falho, por exemplo. Nas formações do inconsciente, "é toda a estrutura da linguagem que a experiência psicanalítica descobre" (Lacan, 1957/1998, p. 498). Num ato falho não é só uma semântica que se revela, mas também, por se tratar de um fenômeno lingüístico, leis que regem a própria linguagem em que ocorrem. Assim, ao retornar à obra de Freud, Lacan demonstra a relação entre o funcionamento do inconsciente e o funcionamento da linguagem. De um lado ele busca as formações do inconsciente (descoberta da psicanálise); de outro, a noção de signo lingüístico de Sausurre (descoberta da linguagem). É, portanto, por meio das formalizações da lingüística que Lacan vai estabelecer a lógica própria do inconsciente.

Entretanto, Lacan observa que no inconsciente há um funcionamento do significante distinto ao que é postulado pelo algoritmo de Saussure. Nesse nível do inconsciente, as palavras se articulam não pelo seu significado, mas pela via do significante - como podemos ver em inúmeros exemplos apresentados por Freud em "Psicopatologia da Vida Cotidiana" -, o que levou Lacan a inverter o esquema do signo lingüístico estabelecido por Saussure. Deste modo,

é ao nível, não mais do signo, mas da cadeia significante, que a discussão conduzida por J. Lacan, em nome da experiência analítica, se institui: a descoberta do inconsciente é a descoberta de um sujeito, cujo lugar, excêntrico para a consciência, só pode ser determinado por ocasião de certos retornos do significante, e pelo conhecimento das leis do deslocamento do significante. O que volta a referenciar e a exterioridade da ordem significante com relação aos sujeitos de enunciados conscientes que acreditamos ser, e sua autonomia, ambas, determinantes para a significação real do que se enuncia em nós. (Ducrot \& Todorov, 1997, p. 328) 


\title{
Marcelo Amorim Checchia
}

A associação entre significantes constitui, assim, uma cadeia significante. Tal cadeia deve ser no mínimo binária, pois nela, segundo Lacan (1957/1998, p. 506), o sentido insiste, mas nenhum dos elementos da cadeia consiste na significação. No inconsciente há, então, uma insistência significante sem relação direta com o significado da palavra dita, por exemplo, num ato falho, mas é justamente a partir dessa insistência que se abre para o sujeito uma outra ordem que não é a da realidade, mas de uma Outra cena, desvelando assim algo da verdade do desejo inconsciente.

Bem, até aqui falamos sobre os elementos lingüísticos (significante e significado) com os quais Lacan procurou formalizar a psicanálise. Mas, se o inconsciente é estruturado como uma linguagem vale observar que além destes elementos lingüísticos, há leis que os governam entre si. Segundo Dor,

\begin{abstract}
estas leis intervêm quando abordamos o 'caráter linear do significante'. Com a cadeia significante vêem-se colocados, $\infty$ m efeito, dois problemas específicos: por um lado o problema das concatenações significativas, por outro lado, a questão das substituições suscetíveis de intervir nos elementos significativos. Estas duas ordens de problema são sancionadas, em toda língua, pela existência de leis internas de natureza diferente, segundo rejam as concatenações ou as substituições. A língua pode, portanto, ser analisada segundo duas dimensões, às quais estão ligadas propriedades específicas: a dimensão sintagmática e a dimensão paradigmática. (1992, p. 33)
\end{abstract}

Em outras palavras, de que tratam essas duas dimensões? São dois eixos espaço-temporais pelos quais o discurso é orientado: “o eixo paradigmático - eixo da seleção, eixo do léxico, do tesouro da linguagem, da substituição e da sincronia, eixo da metáfora - e o eixo sintagmático - eixo da combinação, da contigüidade e da diacronia, eixo da metonímia" (Andrès, 1996, p. 333). Na metonímia um objeto é designado por um termo diferente do que é habitualmente próprio, desde que haja, necessariamente, alguma relação entre os dois termos (ligação esta que se dá via significante, não significado). Deste modo, o processo metonímico impõe um significante novo em relação de contigüidade com o significante anterior (agora suplantado). Entretanto, este significante suplantado não passa sob a barra da significa- 
ção; a função significante, no processo metonímico, opera assim uma perda de significado no trabalho significante. Já no processo metafórico os significantes estão organizados não por contigüidade, mas por substituição, "enquanto o significante oculto permanece presente em sua conexão (metonímica) com o resto da cadeia" (Lacan, 1957/1998, p. 510).

Retomemos agora mais explicitamente as relações entre a psicanálise e a lógica moderna. Ainda neste texto de 1957, “A Instância da Letra no Inconsciente", Lacan propõe uma primeira tópica do inconsciente, definindo-a pelo algoritmo S/s. A partir de então formula o algoritmo da estrutura metonímica e metafórica (1957/1998, p. 518), articulando aí os elementos da linguagem com suas leis:

Foi da co-presença, no significado, não só dos elementos da cadeia significante horizontal, mas de suas contigüidades verticais que mostramos os efeitos, distribuídos, de acordo com duas estruturas fundamentais, na metonímia e na metáfora. Podemos simbolizá-las por:

$$
f\left(\mathrm{~S}^{\prime . . . S} \mathrm{~S}^{\prime}\right) \mathrm{S} \quad \mathrm{S}(-) s
$$

ou seja, a estrutura metonímica, indicando que é a conexão do significante com o significante que permite a elisão mediante a qual o significante instala a falta do ser na relação de objeto, servindo-se do valor de envio da significação para investi-la com o desejo visando essa falta que ele sustenta. O sinal - colocado entre ( ), manifesta aqui a manutenção da barra -,que marca no primeiro algoritmo a irredutibilidade em que se constitui, nas relações do significante com o significado, a resistência da significação.

Eis agora

$$
f\left(\frac{S^{\prime}}{S}\right) S \cong S(+) s
$$

a estrutura metafórica, que indica que é na substituição do significante pelo significante que se produz um efeito de significação que é de poesia ou criação, ou, em outras palavras, do advento da significação em questão. $\mathrm{O}$ sinal + , colocado entre ( ), manifesta aqui a transposição da barra -,bem como o valor constitutivo dessa transposição para a emergência da significação. 


\section{Marcelo Amorim Checchia}

Essa transposição exprime a condição da passagem do significante para o significado (...) confundindo-o provisoriamente com o lugar do sujeito.

Poderíamos agora articular a estrutura metonímica e metafórica, juntamente com seus elementos significante e significado, com a metáfora paterna, até porque esta é considerada por Lacan como o protótipo do processo metafórico. Em suma, Lacan afirma que "o pai é um significante que substitui outro significante", ou melhor, "um significante que substitui o primeiro significante introduzido na simbolização, o significante materno" (1958/1999, p. 180). É evidente que para compreender melhor esta função metafórica do pai seria preciso acompanhar pormenorizadamente cada momento lógico desta operação metafórica. ${ }^{6}$ Contudo, como nosso objetivo inicial é apenas o de procurar compreender porque Lacan se serve da lógica moderna para formalizar a psicanálise, cabe-nos, portanto, somente indicar os avanços alcançados pela formalização desses algoritmos e ressaltar que essa formalização, como vimos acima, fundamenta-se nessa aproximação existente entre o estudo do inconsciente e o estudo da linguagem.

Porém, em relação à metáfora paterna vale ainda ressaltar que esta é uma formalização central na teoria de Lacan. É a partir da metáfora paterna, isto é, da inscrição do Nome-do-pai no Outro da linguagem, que Lacan pôde estabelecer três estruturas clínicas, três modos de negação da castração do Outro: a neurose, a psicose e a perversão. É possível notar assim os avanços permitidos pelo esforço de abstração, pela postulação de algoritmos, de Lacan, que nos permite assim vislumbrar o modo de relação do sujeito com a linguagem - independentemente da consciência ou não que o indivíduo tenha dessa relação. Isso só foi possível porque podemos nos referir ao Outro sem precisar relatar toda a história de um sujeito. O Outro aqui é vazio de

6 Trata-se dos três tempos do Édipo, formalização de Lacan presente no Seminário 5 - As Formações do Inconsciente. 
significado; para cada sujeito há um Outro diferente e para cada um a inscrição do Nome-do-pai no Outro se dará de infinitas maneiras. ${ }^{7}$

Agora se nos atentarmos para o fato de que "o pai é, no Outro, o significante que representa a existência do lugar da cadeia significante como lei, (...) na medida em que a mãe faz dele aquele que sanciona, por sua presença, a existência como tal do lugar da lei" (Lacan, 1958, p. 202), notaremos que há aí mais uma articulação com a lógica matemática, especificamente com a teoria dos conjuntos. O Outro não é um, mas um conjunto de no mínimo dois significantes, uma vez que um significante representa o sujeito para outro significante. As noções de conjunto e conjunto vazio tornam-se assim cruciais para formalização da psicanálise.

Há, porém, um paradoxo na teoria dos conjuntos que também vai ser tratado por Lacan. Trata-se da antinomia de Russell: a de que uma classe não pertence a si própria. Por exemplo, não é possível dizer que a classe dos homens é um homem. Acompanhemos um comentário de Frege a este respeito:

Ninguém dirá que a classe dos homens é um homem. Temos aqui uma classe que não pertence a si própria. Digo que qualquer coisa pertence a uma classe quando pertence ao conceito cuja extensão é essa classe. Concentremo-nos agora no conceito classe que não pertence a si própria. A extensão deste conceito é assim a classe das classes que não pertencem a elas próprias. Abreviadamente chamar-lheemos a classe K. Vejamos agora se a classe K pertence a si própria. Primeiro suponhamos que pertence. Se uma coisa pertence a uma classe então pertence ao conceito cuja extensão é essa classe. Assim se a nossa classe pertence a si própria é uma classe que não pertence a si própria. A primeira suposição conduz assim a uma auto-contradição. Em segundo lugar, suponhamos que a classe $\mathrm{K}$ não pertence a si própria; então pertence ao conceito cuja extensão é a própria classe, e assim pertence a si própria. E aqui uma vez mais temos uma contradição. (Kneale \& Kneale, 1968/1991, p. 660)

7 O que não impediu Lacan de formalizar as estruturas clínicas, justamente porque os algoritmos postulados são vazios de significado, podendo receber uma significação para cada sujeito. 
Doumit (1996, p. 306) nos aponta como tal paradoxo aparece em relação à inscrição do significante do Nome-do-pai no Outro: se o Nome-do-pai é o significante do Outro enquanto lugar da lei, não há aí uma duplicação do Outro - uma vez que o Outro como conjunto de significantes comportaria seu próprio significante, como um catálogo dos catálogos que se menciona a si mesmo? Como diz Doumit (1996, p. 306),

com a escrita $S(A)$, tem-se um significante do Outro que não está no Outro, e a problemática de situar o Outro da lei com relação ao Outro do significante não deixa de lembrar aquela de que Russell trata em sua teoria dos tipos na tentativa de evitar certas antinomias lógicas.

Bem, o mesmo autor afirma que apesar de haver uma relação entre a psicanálise e o progresso formal da lógica matemática, a primeira não partilha necessariamente as suposições doutrinárias dos lógicos. Aí nos deparamos com mais uma dificuldade no estudo da obra de Lacan, uma vez que a lógica do inconsciente formalizada por ele não é a mesma lógica proposta pelos lógicos. Lacan tem que se haver com um paradoxo que compreende o inconsciente e a formalização do inconsciente: "como incluir na estrutura essa falta que é efeito dela?” (Doumit, 1996, p. 309). Além de haver aí uma incompletude do Outro, há também uma inconsistência do Outro:

Lacan chega a falar de inconsistência do Outro. Simples metáfora? Ele escreve: 'se o sujeito é o elemento que descompleta a bateria significante, a falta de gozo faz o Outro inconsistente'. (...) de um lado o sujeito só se escreve como falta de seu próprio significante, de outro lado o significante não poderia esgotar o gozo. Há sem dúvida nesse texto [Subversão do sujeito...] um significante do gozo: Ф, mas há também esse gozo cuja falta inconsistiria o Outro e que Lacan batizaria mais tarde de objeto (a). (Doumit, 1996, p. 309)

Aqui nos deparamos com outros algoritmos e fórmulas da teoria lacaniana: o objeto a, as fórmulas do desejo e do fantasma, etc.. Infelizmente não cabe aqui desenvolver mais esta formalização da psicanálise e sua articulação com a lógica moderna. Isto tudo, lembremos, é somente a título de considerações iniciais. Procurar as articulações entre a lógica moderna e a psicanálise lacaniana é um trabalho instigante e necessário, porém imenso e 
exaustivo e exige um percurso por toda obra de Lacan. Seria preciso, no mínimo, por exemplo, após passar detalhadamente pelos três tempos lógicos do Édipo, percorrer a relação entre gozo, desejo e objeto a, o que nos permitiria avançar para a teoria dos quatro discursos, para a fórmula do fantasma e para as fórmulas da sexuação.

Checchia, M. A. (2004). Introductory reflections on logic and Lacanian theory. Psicologia USP, 15(1/2), 321-338.

\begin{abstract}
In the course of his teaching, Lacan not only made reference to Logic theorists such as Frege and Russel but also extracted from Logic the foundation to formalize psychoanalysis. Why does Lacan resort specificaly to Logic in order to transmit psychoanalysis? What are the relations between Modern Logic and the psychoanalytical experience? This article aims to offer a first approach to these questions.
\end{abstract}

Index terms: Psychoanalysis. Logic (Philosophy). Lacan, Jacques, 19011981. Frege, Gottlob, 1848-1925.

Checchia, M. A. (2004). Considérations initiales sur la logique et la théorie Lacanienne. Psicologia USP, 15(1/2), 321-338.

Résumé: Au cours de son enseignement, Lacan a fait des références à des logiciens et a extrait de la propre logique un fondement pour la formalisation de la psychanalyse. Mais pourquoi Lacan recourt-il justement à la logique pour transmettre la psychanalyse? Quelles sont les relations entre la logique moderne et l'expérience psychanalitique? Dans cet article on abordera ces questions.

Mots-clés: Psychanalyse. Logique. Lacan, Jacques, 1901-1981. Frege. Gottlob, 1848-1925.

\title{
Referências
}

Andrès, M. (1996). Significante. In P. Kaufmann (Ed.), Dicionário enciclopédico de psicanálise (pp. 472-474). Rio de Janeiro: Jorge Zahar. 


\section{Marcelo Amorim Checchia}

Chauí, M. (1997). Convite à filosofia. São Paulo: Ática.

Chauí, M. (2002). Introdução à história da filosofia 1. São Paulo: Companhia das Letras.

Darmon, M. (1994). Ensaios sobre a topologia lacaniana. Porto Alegre, RS: Artes Médicas.

Doumit, É. (1996). Lógica. In P. Kaufmann (Ed.), Dicionário enciclopédico de psicanálise (pp. 297-315). Rio de Janeiro: Jorge Zahar.

Ducrot, O., \& Todorov, T. (1997). Dicionário enciclopédico das ciências da linguagem. São Paulo: Perspectiva.

Kneale, W., \& Kneale, M. (1991). O desenvolvimento da lógica. Lisboa: Fundação Calouste Gulbenkian. (Trabalho original publicado em 1968)

Lacan, J. (1981). O seminário. Livro 1: Os escritos técnicos de Freud. Rio de Janeiro: Jorge Zahar. (Trabalho original publicado em 1954)

Lacan. J. (1992). O seminário. Livro 17: O avesso da psicanálise. Rio de Janeiro: Jorge Zahar. (Trabalho original publicado em 1958)

Lacan, J. (1998). Função e campo da fala e da linguagem em psicanálise. In J. Lacan, Escritos (pp. 238-324). Rio de Janeiro: Jorge Zahar. (Trabalho original publicado em 1953)

Lacan, J. (1998). A instância da letra no inconsciente ou a razão desde Freud. In J. Lacan, Escritos (pp. 496-533). Rio de Janeiro: Jorge Zahar. (Trabalho original publicado em 1957)

Lacan. J. (1999). O seminário. Livro 5: As formações do inconsciente. Rio de Janeiro: Jorge Zahar. (Trabalho original publicado em 1958)

Nogueira, L. C. (1997a). A entrada na relação analítica. Psicanálise e Debate, 2(2), 16-21.

Nogueira, L. C. (1997b). A psicanálise: Uma experiência original; o tempo de Lacan e a nova ciência. Tese de Livre-Docência, Instituto de Psicologia, Universidade de São Paulo, São Paulo.

Nogueira, L. C. (2002). Aula de pós-graduação ministrada no Instituto de Psicologia da Universidade de São Paulo. (Trabalho não publicado)

Singh, S. (2000). O último teorema de Fermat. Rio de Janeiro: Record.

Recebido em 09.06.2004

Aceito em 06.08.2004 